\title{
A Study on Bangladeshi IT freelancers: A Survey
}

\author{
Argho Das \\ Dept. of CS \\ American International University- \\ Bangladesh (AIUB)
}

\author{
Asm. Habib Ullah \\ Dept. of CS \\ American International University- \\ Bangladesh (AIUB)
}

\author{
Gazi Rifat Fatima \\ Dept. of CS \\ American International University- \\ Bangladesh (AIUB)
}

\author{
AZM Ehtesham Chowdhury \\ Dept. of CS \\ American International University- \\ Bangladesh (AIUB)
}

\author{
Dipon Kumar Das \\ Dept. of CS \\ American International University- \\ Bangladesh (AIUB)
}

\author{
Md Shamsur Rahim \\ Dept. of CS \\ American International University- \\ Bangladesh (AIUB)
}

\begin{abstract}
The software and IT service industry of Bangladesh are expected as the significant destination for business process outsourcing. Two vital questions arise, what are the present conditions of freelancing in Bangladeshi IT sectors and what are the challenges a freelancer is facing? To answer these questions, a survey has been conducted by the authors to recognize the present conditions and problems in the freelancing sector of Bangladesh. A group of 46 freelancers who are staying in Bangladesh, participated in this survey from June to November 2017. To find great insights, authors have made a questionnaire which is divided into six segments based on the freelancers' intrinsic and extrinsic properties. From the survey results, the authors prepared a dataset. In this paper, an analysis from the dataset is shown to illustrate the current state of IT freelancing sector and the obstacles for freelancers to augment himself.
\end{abstract}

\section{Keywords}

Freelancers, Preliminary Survey, IT Sector, Software Development, Income Stability.

\section{INTRODUCTION}

We are living in a globalized world where economical flows, communications and the operations of multinationals from all parts of the world have displaced the point of view of the international business environment. In the past, all over the world, business and work were much difficult. Only for those, who traveled from one country to other countries with the hope of getting jobs. At that time, people used to go from one place to another place for business and working purpose. But it was difficult for them. Later, when there are borderless marketing or business benefits, everyone starts to get good jobs or business from different countries. As a result, sitting in another place, people can work in different organizations in different countries like America. The unemployment rate has decreased and self-employment rates have increased due to outsourcing and freelancing. At the same time, the economic flows of a country are changing. Thurik et al showed in his paper that the difference between self-service and unemployment rate [1]. Saleh explained in his paper that selfservice is most important for economic growth it will also reduce poverty in a magical way [2].

A freelancer or freelance worker is a term usually utilized for a man who is independently employed and isn't really dedicated to a specific boss in long term. Freelancing is literally popular word nowadays. Ross \& Burke said: "There is no legal definition what freelancer is, indeed it is often a self-descriptive term" [3]. Most of the people thinks that valuable knowledge of information technology and computer science is ordained to be a freelancer yet Panko express not to think about the undergraduate degree as the main part of freelancing by analyzing the report of the U.S. and Western Europe [4].

Freelancers are sometimes working for a company or an agency that provides freelancer's effort to the clients. Other freelancers work independently or visit some websites to get work. According to Gandia's survey 149 freelancers who work in diverse fields. The absolute reason for this survey was to know deeply approach of freelancing. His survey was about the service of a freelancer, identities of freelancers, challenges faced by freelancers [5]

There are different categories of a site to earn from online and there are different categories of projects where some projects are annual, some projects are monthly and some of them are daily work. Some freelancers such as students, service holders are also depending on online earning. Earning from online helps to save time assist to overcome the economic status of a country. Kuek et al. explained freelancing as a trendy way for social development, self-development, government's development, and development in the digital economy [6]. Stupnikova, Vanyashina, and Serkova showed on the condition and the way of freelancing in Russia [7].

The outsourcing trend has earned so much popularity in Bangladesh that people from different categories of the society are joining this profession. There are a lot of different types of outsourcing in Bangladesh like:

- Professional Outsourcing Service

- Manufacturing Outsourcing Services

- Process Specific Service

- Operational Outsourcing Service

- IT Outsourcing

- Multi-sourcing

- BPO (Business Process Outsourcing

- Project Outsourcing

- Offshore Outsourcing

- KPO (Knowledge Process Outsourcing) 


\section{- Local outsourcing \\ - Nearshore outsourcing}

The authors' perspective is to present the conditions of freelancing in Bangladesh. So, they are characterizing the participants. But it is not an easy job of distinguishing the participants. So, they are differentiating students, stakeholders, everyone who is involved in industry or work for a company or a self-employed.

Though Bangladesh has achieved their nationality for 50 years, the ICT sector of Bangladesh has been got promoted from 1997 in the economic sector. As BASIS survey, Shaik Al Mahmood justified in his paper that the improvement of Bangladeshi IT industry is $20 \%$ to $30 \%$. The IT sector of Bangladesh is promoting globally. From the report and investigation of many freelancing areas, it is said that Bangladeshi freelancers are rapidly growing and making their places in every freelancing marketplace [8]. Now Bangladesh also has a freelancing site "Balancer" in this country [9].

In Bangladesh Upwork, freelancer.com is a common site. In this paper, Hassan Tanvir Mansur recognizes that, how many students are involving with freelancing, how they spend their time on the internet, how they get their payment etc. [10]. Old geographic boundaries have disappeared mutually of the global development of low-cost computing and internet communications. It reinforces David Ricardo's 1817 justification of comparative advantage that says free enterprise allows economies benefit from the efficiency of global specialization [11]. According to the Kearney Global Services Location Index, Bangladesh is at 22nd place with performing 5.31 and compared to the report of the country has managed to escape 4 spots in ranking [12].

The information which was got from the survey may address potential research difference in the field of outsourcing. This paper reported the observations obtained from 46 respondents who successfully completed the entire questionnaire.

Although the sample population may seem to be relatively small, the authors believe that in terms of Bangladeshi Software and IT Industry, this sample is enough to obtain interesting information for previous studies of various countries. Besides the consistency of the data has encouraged the writers to present the information in this paper. The rest of the paper is formed as follows:

* Section 2 relates the objective of the survey and the sample selection method.

* In section 3 the result is presented obtained from the survey.

* In section 4 there is a clarification about the information also about the survey and conclude.

\section{RELATED WORKS}

\subsection{Survey Objectives}

- History of Freelancing

- The way of freelancing work

- $\quad$ Prerequisite to freelancing

- How to start online freelancing

- How to manage a client.

- What to do

- Payment System
- What types of service to be done?

\subsection{Survey Description}

The aim of this survey was to find out the existent situation of the freelancing sector of Bangladesh. Potential research differences in the field of outsourcing may be addressed by the information which is found from the survey. It can bring a positive variation in IT sector of Bangladesh and also the economic development. For collecting data, some dataset was made which helped us to collect information from freelancer or freelancing company. Six sections of data were made which based on a different field of freelancing. The introduction part was about basic information about a freelancer or freelancing company. The six sections which made the survey easy are summarized below.

\section{Section A-Basic Information:}

This is the first section of the survey. In this part, some questions were made which based on basic information about a company or a freelancer. This basic information is related to personal information. This sector is the proof of the freelancer's or company's availability.

Section B-Freelancing:

It is the second section of the survey. This section is directly related to freelancing. This part is based on freelancing services. From this part, it was tried to know about the most popular sector of the freelancing region in Bangladesh. Though most of the freelancers of Bangladesh are connected with web developing or graphics designing or SEO or others, all of them are independent workers.

Section C-Income:

This is one of the major parts of the survey. This part presents the average income of a freelancer. This part also gives us a plain idea about safe, secured and easiest payment system, payment method of freelancing.

Section D-Workload:

Because of overpopulation, almost $7 \%$ to $10 \%$ of people are not getting a job as well they are working as a freelancer nationally or internationally [13]. This part explored the workload of a freelancer or freelancing company. The manageability of work and workload are shown in this sector. Which field or method is easy to be a successful freelancer are also defined in this part.

Section E-Communication:

Communication is the main base for a freelancer. They can communicate with the client through the social network, phone call or many freelancing sites. Which way is easy for a freelancer to contact with clients is described in this section by some question answering. Besides which internet connection is better and what should be the speed of the net connection are described.

Section F-Work area:

This is the final part of a survey and the most essential part also. This part is based on companies or freelancers work area. Which software applications are used and which language is preferred are described in this part. Sometimes companies or freelancers ask some question to their clients about their requirements. This section also about the form of the question which faced by the clients.

\subsection{Survey Method}

As a survey method, online interview comprised of both frank and closed-type questionnaires is used. A Google form was created and posted it online. The survey interviews were held online. So, it was very much flexible for the interviewee. 
$\mathrm{He} / \mathrm{she}$ can attend the survey where he/she wants. The interviewee also can edit or change the answer after submitting. Each interview took 25-30 minutes on average. The quality of data received from interviewee depends on his/her ability to work. So, for the same question, a different answer was received from a different person. It's affected survey to get the idea about the running situation of freelancing in Bangladesh. Finally, the secret of the respondents and the company was assured.

\subsection{Survey Selection}

This survey was aimed at present and future of freelancers in Bangladesh. At first, a draft questionnaire was prepared. After that, A Google form was built and share it with all friends through online and offline. This survey link was sent in the different Facebook group. It was sent through mail and SMS to honorable faculties. This survey was held among two shapes of participants: the first priority was the organization who work as a freelancer, the second was individual freelancers.

As a qualitative research was performed whose aim was to understand and investigate differences, so random sampling over other sampling methods has been chosen. At first, more than 200 interviewees were invited through emails, SMS and group posts to take part in the survey but only 46 organizations/ individuals responded positively. The participation rate may seem low but the authors believe that this sample would be enough to represent the whole country.

\section{SURVEY RESULT}

\subsection{Basic Information}

This section was aimed to gather basic information about the interviewee, his/her company and their thinking. Questionnaires were tailored to accomplish the task. Firstly, the name of the interviewee and the name of the company were asked. After that, they were asked about their and their organization and work experience (years). At last of this section, they were asked about their thinking on freelancer's mistakes when applying for jobs which were multiple choice open-ended questions.

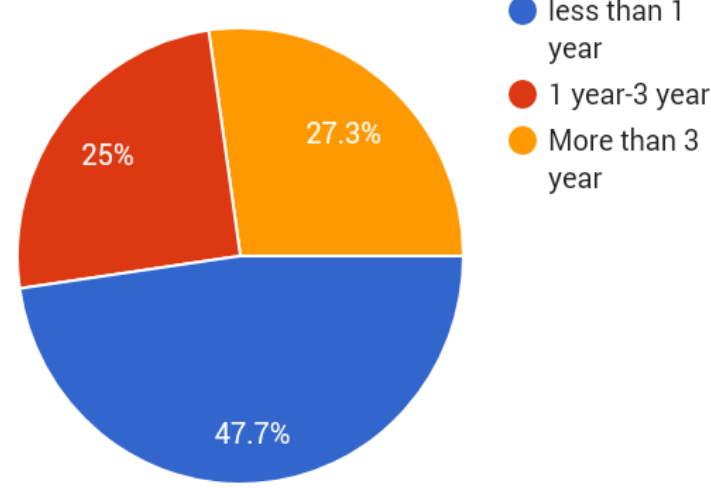

Fig. 1: How long has your company been in business?

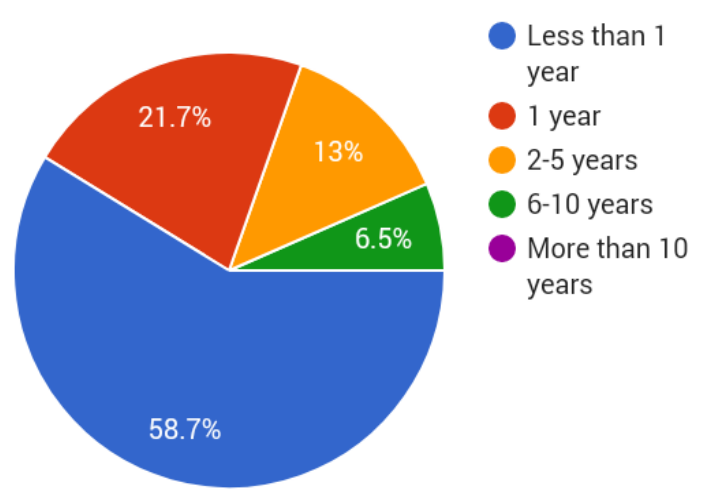

Fig. 2: How long do you working as a freelancer?

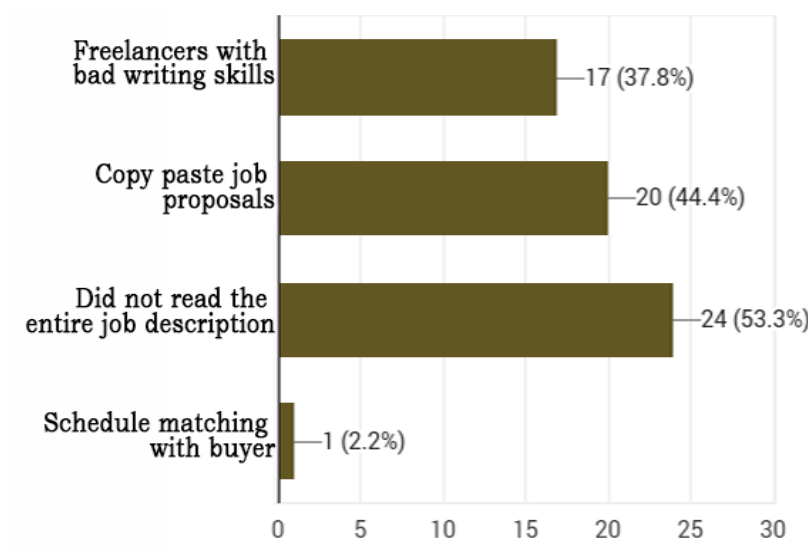

Fig. 3: Common mistakes freelancers make when applying for jobs?

Out of the 46 respondents, 11 were individual freelancers, 32 were organizations. This 32 companies, 23 are startup companies, 11 were struggling companies and 12 were renowned companies Figure 1. Into these individual interviewees, $27(58.7 \%)$ were new in this sector, 19(21.7\%) were serving from $1-10$ years and there was no one who was working more than 10 years Figure 2. This interviewee thought that they didn't read the entire job description which was seemed the common mistakes when applying for a job Figure 3.

\subsection{Freelancing}

This section mainly investigated the likes and dislikes of freelancers, their work area, their satisfaction as a freelancer and the reason behind becoming a freelancer. This is a multiple-choice open-ended question.

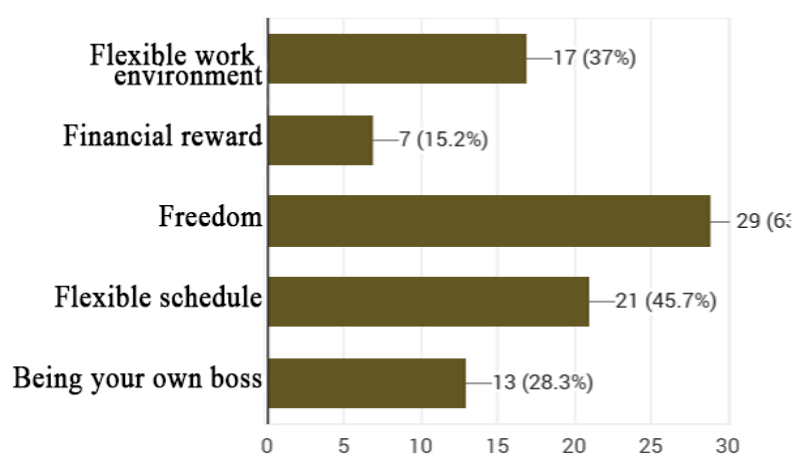

Fig. 4: What do you like most about freelancing? 


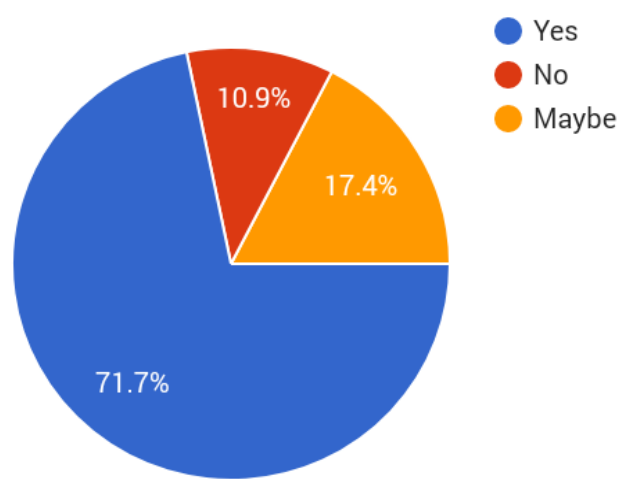

Fig. 5: Are you happy with your choice of freelancing?

From 46 interviewees, 29 interviewees liked the freedom of freelancing Figure 4. The next Question was that he/she was happy or not. 33 said that they were happy Figure 5. The last questions in this section were about the reason behind choosing the path to become a freelancer 24 say they want to start a new business.

\subsection{Income}

In this section, they were asked about income stability, risk in the payment system, average monthly income, payment method and payment currency they often use from the freelancers. In a nutshell, the main goal of this part was to know each and everything about income process in this section.

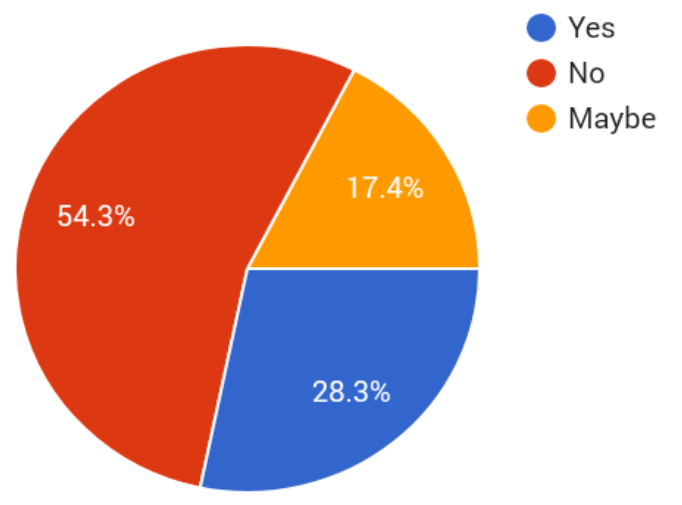

Fig. 6: Is the income stable?

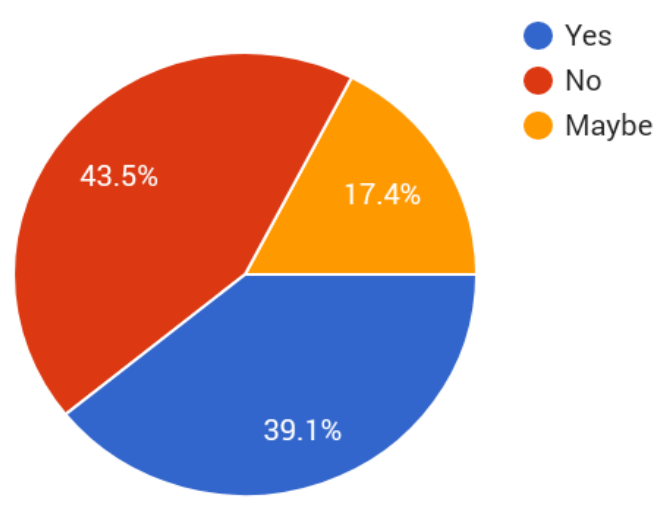

Fig. 7: Is there any risk about payment system?

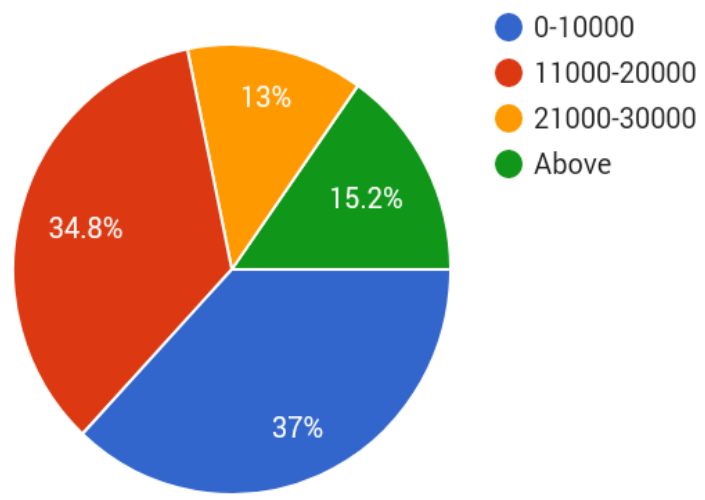

Fig. 8: In the past years, how much money did you make freelancing?

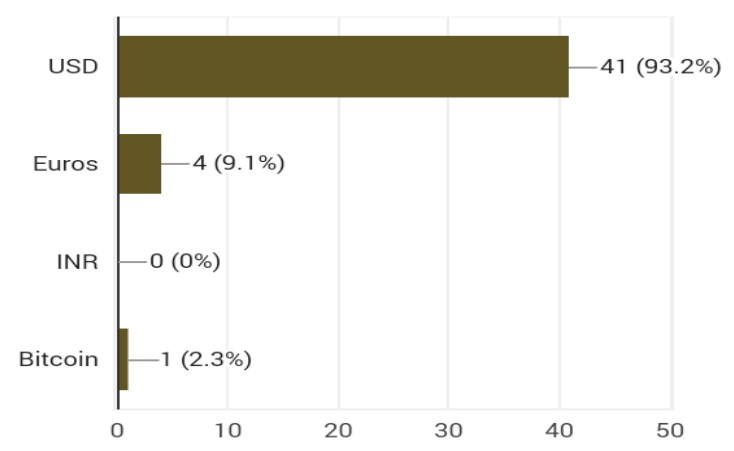

Fig. 9: Cross-currency billing when freelancing for international clients.

From these 46 interviewees, (54.3\%) 25 says income is not stable Figure 6. They were asked about the risk in the payment system $20(43.5 \%)$ says there is no risk Figure 7. From this survey, it is known that in this country maximum freelancer earn billow 10,000tk per month. In this survey (37\%) 17 participants earn below 10,000tk Figure 8. Almost $20(51.3 \%)$ participants used the PayPal payment method. For cross currency billing 41(93.2\%) freelancer used USD Figure 9.

\subsection{Work Load}

This section depends on freelancers thinking about work pressure and how much satisfied or dissatisfied they are with this kind of job. They were also asked about their company size, their work process and methods were followed by them to find work.

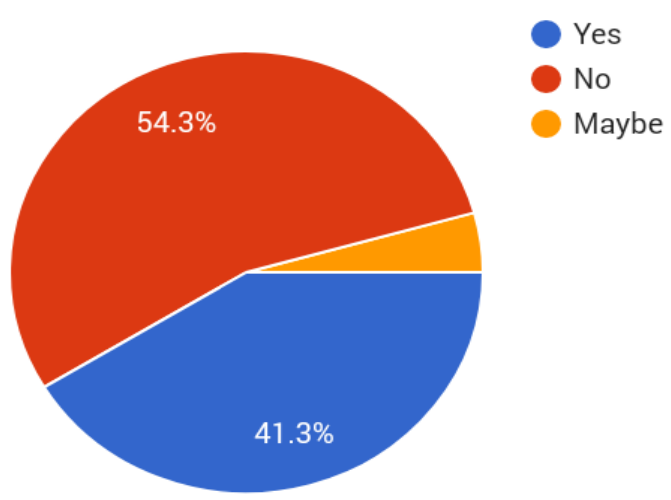

Fig. 10: Is the workload stable? 


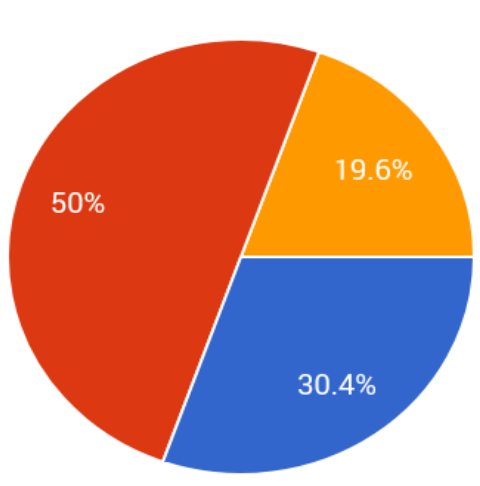

Yes

No

Maybe

Fig. 11: Is it easy to manage work alone?

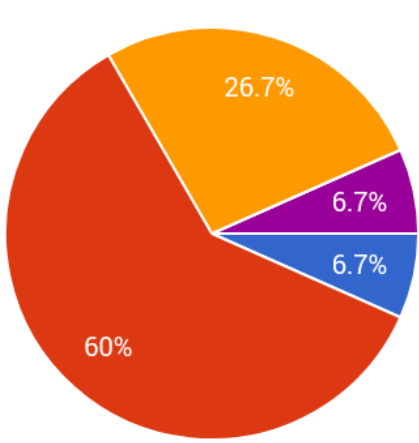

Very satisfied

Satisfied

Neutral

Dissatisfied

Very

dissatisfied

Fig. 12: How satisfied are you with your level of compensation as a freelancer?

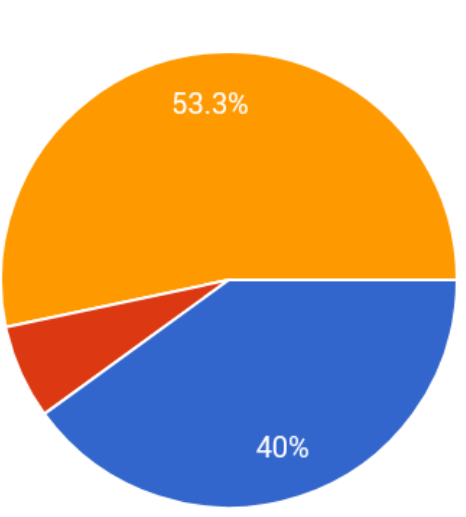

Quality

Speed

Both

Fig. 13: What is most important to you?

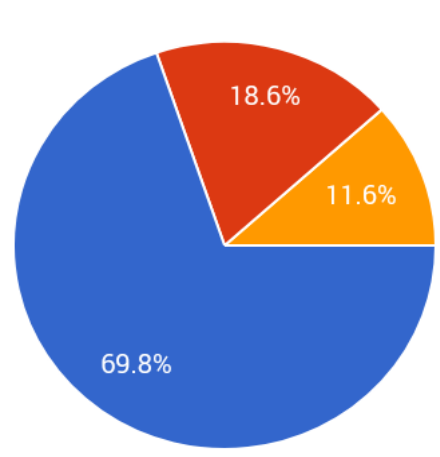

Small

Medium

Large

Fig. 14: What is the size of your company?

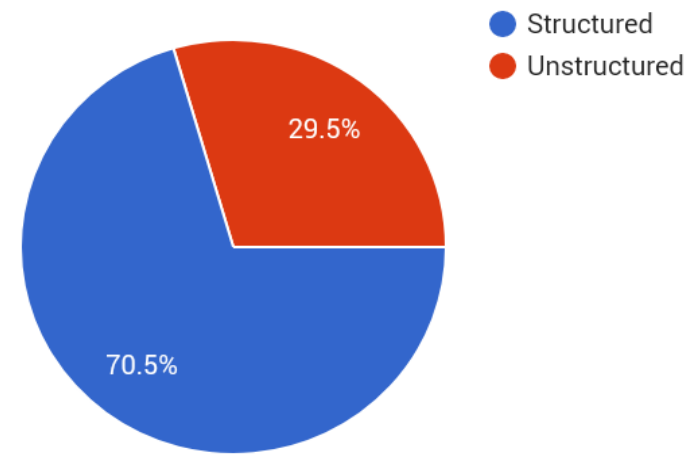

Fig. 15: Is your preferred work process structured, or unstructured?

From these 46 people, 25 (54.3\%) thinks the workload is not stable Figure 10. $23(50 \%)$ people said it is difficult to manage work alone Figure 11. $28(60 \%)$ people are satisfied as a freelancer Figure 12. From next set of questions, it was got to know that both quality and speed are most important in this country are thought by $25(53.3 \%)$ people Figure 13 . In this survey 33 small, 8 medium and 5 large companies participate in Figure 14. Form these 46 persons most of them 33 (70.5\%) preferred a structured process for work Figure 15.

\subsection{Communication}

If freelancer cannot communicate with people, they could not be able to complete their jobs even they could not get any job. They were asked which freelancing site they are working, their technic for appointing employee, which method they use for communication, what type of internet connection they used, average bandwidth they needed, how many data they consumed per month, how much internet disruption they felt. Finally, asked that the time zone regarding problems were affecting their work or not.

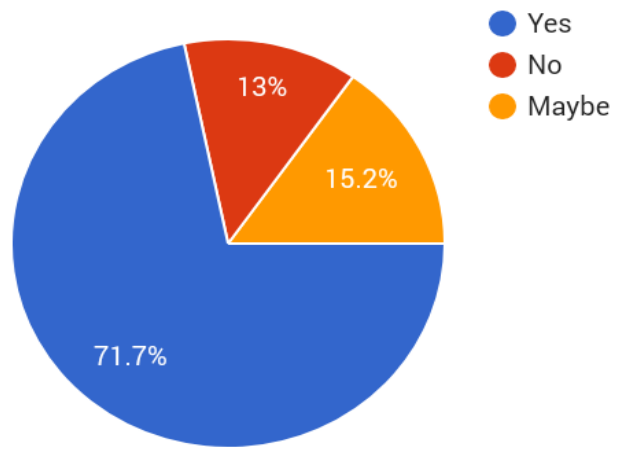

Fig. 16: Is it a good way to contract with people?

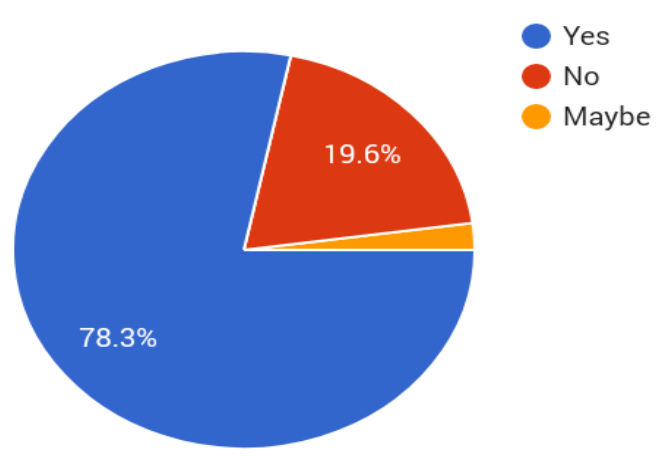

Fig. 17: Have you ever used a freelance website to look for work? 


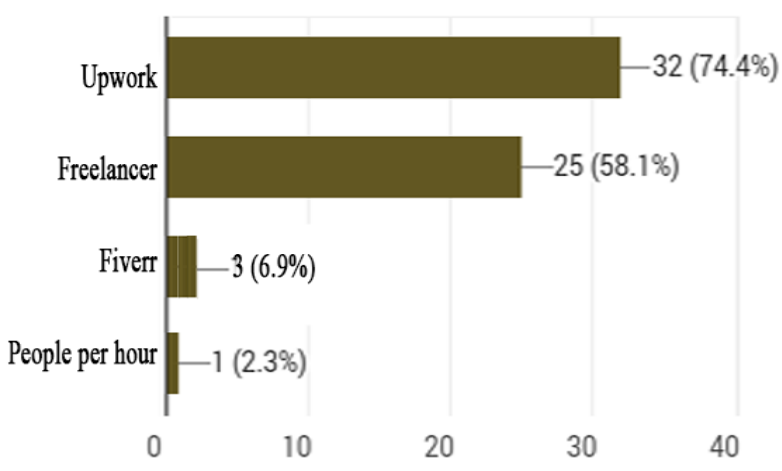

Fig. 18: With which freelancing site you are working with?

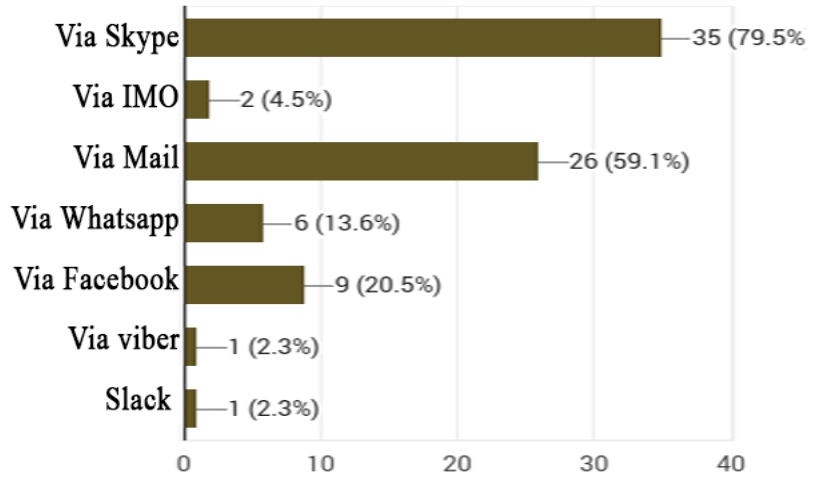

Fig. 19: How do your company communicate with clients?

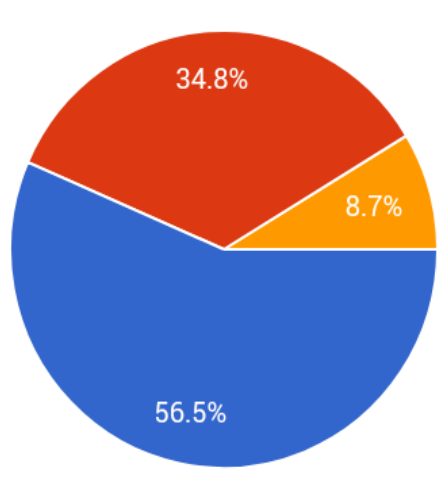

Broadband (dedicated)

Broadband

(Shared)

3G/3.9G/4G

Fig. 20: What type of internet connection you have used?

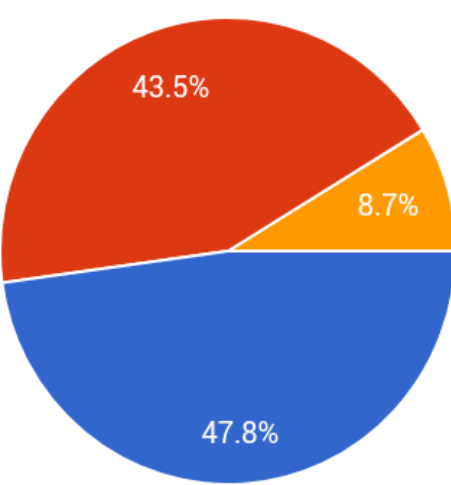

$1 \mathrm{mbps}-3$

mbps

$4 \mathrm{mbps}$ -

$10 \mathrm{mbps}$

$>10 \mathrm{mbps}$

Fig. 21: How much average bandwidth you have needed?

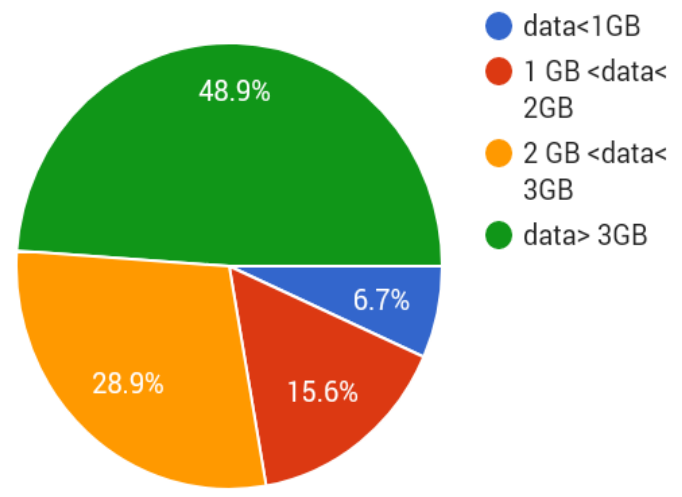

Fig. 22: How much internet data you consume in a month regarding freelancing $(\mathrm{R} \& \mathrm{D}$, Development)?

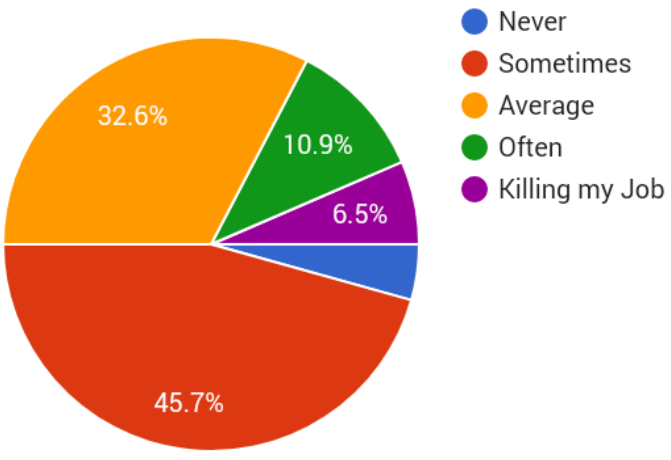

Fig. 23: How frequent disruption feel in internet services?

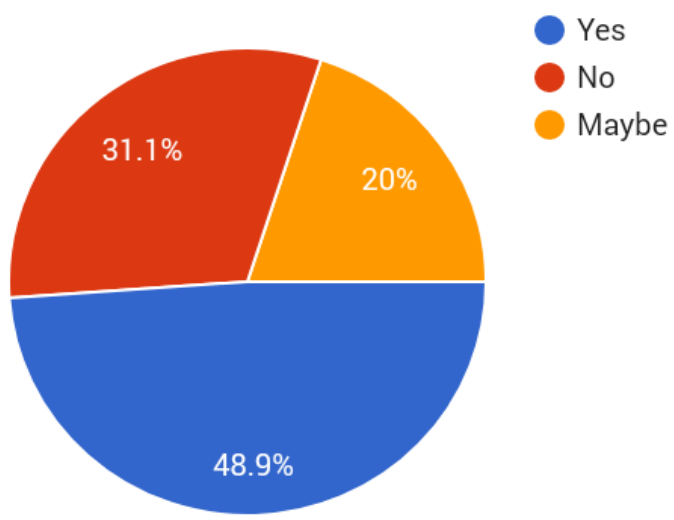

Fig. 24: Do you feel time zone regarding communication may affect you much on your mental and physical health?

Among 46 freelancers, 33 (71.7\%) thought it as a good way to contract with people Figure 16. $36(78.3 \%)$ of them used freelancing website to look for work Figure 17. Upwork is the most used site in this country in this survey $36(74.4 \%)$ participants use Upwork Figure 18. 37 (79.1\%) interviewee used online advertising to appoint employee Figure 19. 37 (79.5\%) persons used skype for communication. A huge number of freelancers in this country used the dedicated broadband internet. From this survey, it is 26 means (56.5\%) Figure $20.47 .8 \%$ of people from this survey needed $1-3 \mathrm{mbps}$ bandwidth Figure 21. 23 (48.9\%) participants used more than 3 GB data per month Figure 22. 21 (45.7\%) people sometimes feel a disruption on the internet and almost $17.4 \%$ people think it is a big headache for them Figure 23. 23 (48.9\%) people things time zone regarding problem were affecting them mentally and physically Figure 24 . 


\subsection{Work Area}

In this area, it was tried to identify in which area of freelancing, freelancers of this country work more. It was interesting to know about the percentage of their profit, types of software they use, language or framework they use for freelancing. Finally, they were asked if they arranged an interview with clients or not.

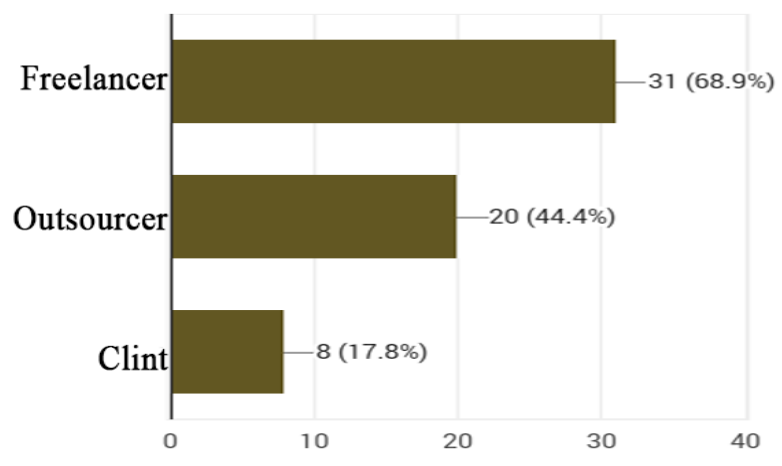

Fig. 25: What kind of business is your company in?

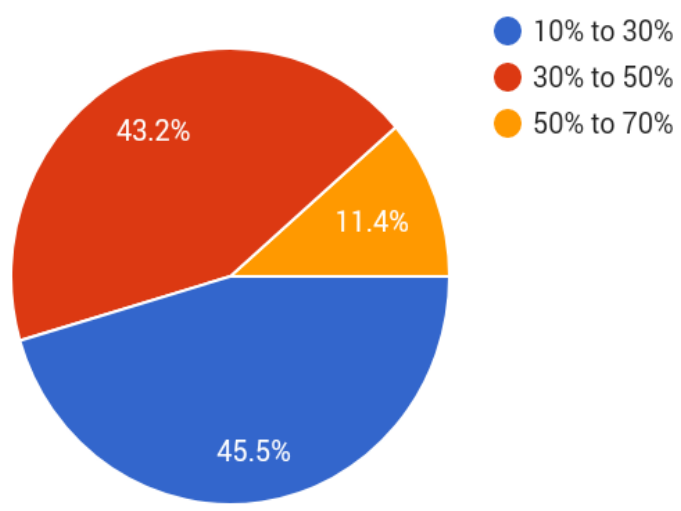

Fig. 26: Percent of profit?

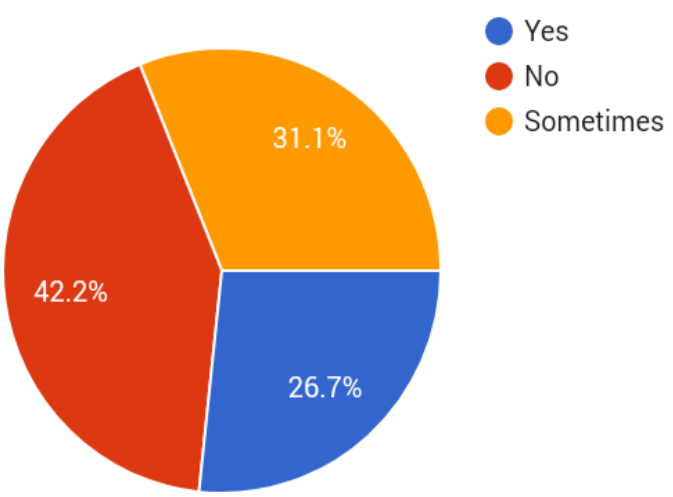

Fig. 27: Do you interview prospective clients?

In this survey $31(68.9 \%)$ worked as a freelancer Figure 25. From this survey, it is known that $22(45.5 \%)$ peoples profit margin is from 10-30\% Figure 26. $27(62.8 \%)$ people and his company work in web development. 30 people in this survey used WordPress software for their work. The next query was which language or framework they used. 27 (62.8\%) said that they were working in PHP. Do they arranged an interview with clients was also asked by us. $20(42.2 \%)$ said no about the arrangement of an interview for clients Figure 27.

\section{DISCUSSION}

This survey was about the condition of freelancer in Bangladesh. To establish this thesis on it freelance sector of Bangladesh, a questionnaire with six groups of questions were created. A dataset was created which contains the relevant data to freelancing, their way of working, working experience in this field. The first part of the question was about the basic information of the freelancer or the freelancing company. The second part was related to freelancing fields. The questions of the third part were asked about their income from this selfemployed job. The fourth part of the question set was most important which is the workload of a freelancer. Fifth number part was communication between clients and freelancer. And then they were asked some questions about the work area from where freelancers got a contractual job from clients. The form was tried to be in reach of those people who are attached with freelancing. Many of them helped us by their opinion about this sector. Some people are happy with this selfemployed job. They are maintaining their life as they want. Moreover, some are not happy because of flawless work and income.

\section{CONCLUSION}

Though Bangladesh is not much updated in the IT sector, the response of the freelancing side is too good. New developing thoughts are arising among people. At present People are interested in freelancing and they are building their career with online outsourcing jobs in Bangladesh. Through this survey, the state of Bangladesh was tried to predict and gladly a positive result came from the survey. Many people are getting engaged with freelancing, they are happy and profit in also enough which are positive sides but freelancing income instability, unstable workload, time zone problem are negative sides for freelancers. From this survey, it can be assumed that the future freelancing state of this country. For bright future in freelancing of it, sector people need government help which will make freelancers step stronger. Besides, the economic progress will be improved positively. After researching the data, proper knowledge is accepted that people of Bangladesh are growing their ability in IT sector and it is a positive sign for this country.

\section{REFERENCES}

[1] R. Thurik, M. Carree, A. van Stel and D. Audretsch, "Does Self-Employment Reduce Unemployment?", SSRN Electronic Journal, 2007.

[2] Saleh, A. Z. M. (2014), "State of Unemployment and Poverty", Bangladesh Economic Update, vol. 5, no.5, May 2014.

[3] Ross, P. \& Burke, A. (2014), "The Freelancing Agenda: A Charter \& Policy Proposals", LFIG, Retrieved on August 25, 2016.

[4] R. Panko, "IT employment prospects: beyond the dotcom bubble", European Journal of Information Systems, vol. 17, no. 3, pp. 182-197, 2008.

[5] Gandia, E. (2012), "Freelance Industry Report: Data and Analysis of Freelancer Demographics", Earnings, Habits and Attitudes.

[6] Kuek, S. C., Paradi-Guifold, C., Fayomi, T, Pina, P. and Singh, M. (2015), "The Global Opportunity in Online Outsourcing", World Bank Group.

[7] Stupnikova, O., Vanyashina, E. and Serkova, N. (2015), "Freelancing as a new form of staff employment", 
Journal of Economics and Social Sciences, Tomsk Polytechnic University.

[8] N. Hasan, "PROGRESS AND PROSPECT OF FREELANCING BUSINESS IN BANGLADESH", meetnazmulhasan, 2017. [Online].

Available:https://meetnazmulhasan.wordpress.com/2012/ 06/12/progress-and-prospect-of-freelancing-business-inbangladesh/. [Accessed: 02- Dec- 2017].

[9] "Clarity, by Balancer", Balancer, 2017. [Online].

Available: https://balancer.bandcamp.com/. [Accessed: 05- Dec- 2017].

[10] Hassan Tanvir Mansur, "Freelancing in Bangladesh", International Journal of Scientific \& Engineering Research, vol. 5, issue 9, September-2014.

[11] MD. Atiqul Islam, "Freelancing and its Future potential for Bangladesh" (3.1-3.2).

[12] Md Shamsur Rahim, Md. Hasibul Hasan, AZM Ehtesham Chowdhury, Shovra Das, "Software Engineering Practices and Challenges in Bangladesh: A Preliminary Survey", Department of Computer Science, American International University-Bangladesh, Dhaka, Bangladesh.

[13] Muhammad Ataur Rahman1 and Mohammad Masudur Rahman1, "Factors, Impacts, Problems and Solutions of Freelance Earning in the context of Bangladesh", Business \& Entrepreneurship Journal, Dept. of Business Administration, East West University, Bangladesh, vol. 6 , no. 1, 2017, 1-13.

\section{AUTHOR'S PROFILE}

Argho Das completed B.Sc. in Computer Science \& Engineering from American International UniversityBangladesh, Dhaka, Bangladesh. Her current research interest includes Cyber Security, Software Engineering, Information
System, Intelligent Systems and Human-Computer Interaction.

Gazi Rifat Fatima completed B.Sc. in Computer Science \& Engineering from American International UniversityBangladesh, Dhaka, Bangladesh. Her current research interest includes Data Science, Software Engineering, Information System, Intelligent Systems, and Human-Computer Interaction.

Dipon Kumar Das completed B.Sc. in Computer Science \& Engineering from American International UniversityBangladesh, Dhaka, Bangladesh. His current research interest includes Data Science, Software Engineering, Information System, Intelligent Systems, and Human-Computer Interaction.

A S M Habib Ullah completed B.Sc. in Computer Science \& Engineering from American International UniversityBangladesh, Dhaka, Bangladesh. His current research interest includes Virtualization, Programming Languages and environments, Hardware-software borderline, Intelligent Systems and robotics, and Human-Computer Interaction.

AZM Ehtesham Chowdhury completed B.Sc. in Computer Science \& Engineering and M.Sc. in Computer Science from American International University-Bangladesh, Dhaka, Bangladesh. His current research interest includes Data Science, Data Analytics, Software Engineering and Mining, Intelligent Systems. Computer Vision, Pattern Recognition, Human Centred Technology (HCT), and Human Centred Design (HCD).

Md Shamsur Rahim obtained his B.Sc. in Computer Science \& Software Engineering and M.Sc. in Computer Science from American International University Bangladesh, Dhaka, Bangladesh. His current research interest includes Data Science, Data Mining and Software Engineering. 